\title{
PREVALENCE OF Enterococcus SPECIES FROM VARIOUS CLINICAL SPECIMENS IN SHRI SATHYA SAI MEDICAL COLLEGE AND RESEARCH INSTITUTE WITH SPECIAL REFERENCE TO SPECIATION \& THEIR RESISTANCE TO VANCOMYCIN
}

\section{SUNILKUMAR JADA* AND KARTHIKA JAYAKUMAR}

Department of Microbiology, Shri Sathya Sai Medical College \& Research Institute.

*Corresponding Author: Email- sunilkumar.jada@gmail.com

Received: May 07, 2012; Accepted: May 21, 2012

\begin{abstract}
-
Introduction- Enterococci are part of the normal intestinal flora of humans and animals but have also emerged as important pathogens responsible for serious infections in hospital and community acquired infections. According to recent surveys, Enterococci remain in the top 3 most common pathogens that cause nosocomial infections.

Aim- To process all the clinical samples from various departments in our hospital, for the isolation of Enterococci sp. To speciate the isolates \& to have the resistance pattern of the isolates to Vancomycin

Methods and Material- A total of 928 samples were collected from both out patients and in patients in all clinical departments and transported to microbiology laboratory. Specimens were processed by inoculating on to Mac Conkeys agar, blood agar, nutrient agar and Pfizer selective media and incubated at $37{ }^{\circ} \mathrm{C}$ for 24 - 48 hours. Enterococci were identified by their typical arrangement in Gram stain, Bile esculin test and salt tolerance test. Speciation was done by subjecting the isolates to a battery of biochemical tests. Antimicrobial susceptibility patterns were determined by performing Kirby-Bauer disc diffusion method and Minimum Inhibitory Concentration (MIC) values were identified by Tube \& Agar dilution method.

Results- A total of 928 samples. Among these, 647 (69.72\%) were culture positive with different isolates and 281 (30.28\%) were culture negative. Among 647 culture positive cases, 100 (15.46\%) were Enterococcus faecalis. Antimicrobial susceptibility \& MIC done as per standard protocols. The E. Faecalis showed $99 \%$ sensitive to Vancomycin. The resistance to Vancomycin was further confirmed by MIC both Agar \&Tube dilution methods, in which the MIC was: $32 \mu \mathrm{g} / \mathrm{ml}$ in one isolate.

Conclusions- Species level identification of Enterococcus is not only important for epidemiological study, but also for analysing the drug resistant pattern. Effective detection of Vancomycin resistance in laboratory helps in reducing the morbidity and mortality due to VRE in hospitalized patients.
\end{abstract}

Key words- Blood agar, Mac Conkeys agar, Bile esculin, Vancomycin resistant Enterococci, Minimum inhibitory concentration.

Citation: Sunilkumar Jada and Karthika Jayakumar (2012) Prevalence of Enterococcus species from various clinical specimens in Shri Sathya Sai Medical College \& Research Institute with special reference to speciation and their resistance to Vancomycin. International Journal of Medical and Clinical Research, ISSN:0976-5530 \& E-ISSN:0976-5549, Volume 3, Issue 4, pp.-154-160.

Copyright: Copyright@2012 Sunilkumar Jada and Karthika Jayakumar. This is an open-access article distributed under the terms of the Creative Commons Attribution License, which permits unrestricted use, distribution and reproduction in any medium, provided the original author and source are credited.

\section{Introduction}

Enterococci are part of the normal intestinal flora of humans and animals but have also emerged as important pathogens responsible for serious infections in hospital and community acquired infections. The genus Enterococcus includes more than 17 species, but only a few cause clinical infections in humans [1].
Enterococci were originally classified as enteric gram-positive cocci and later included in the genus Streptococcus. In the 1930s, with the establishment of the Lancefield serological typing system, Enterococci were classified as group D streptococci and were differentiated from the non-Enterococcal group $D$ streptococci such as Streptococcus bovis by distinctive biochemical 
characteristics [2].

Enterococcus faecalis and Enterococcus faecium are the most prevalent species cultured from humans, accounting for more than $90 \%$ of clinical isolates. Other Enterococcal species known to cause human infection include Enterococcus avium, Enterococcus gallinarum, Enterococcus casseliflavus, Enterococcus durans, Enterococcus raffinosus and Enterococcus mundtii. $E$ faecium represents most vancomycin-resistant Enterococci (VRE)[1].

Infections commonly caused by Enterococci include urinary tract infections, endocarditis, bacteremia, catheter-related infections, wound infections and intra-abdominal and pelvic infections. Intestinal colonization with resistant enterococcal strains is more common than clinical infection. Colonized patients are a potential source for the spread of organisms to the health care workers, the environment and other patients [3]. Enterococci can survive for long periods on environmental surfaces, contributing to their transmission. VRE have been isolated from all objects and sites in health care facilities[4].

For colonization development and infection with VRE, antimicrobial and non antimicrobial risk factors have been identified[5].

Third-generation cephalosporins, aminoglycosides, aztreonam, ciprofloxacin, imipenem, clindamycin and metronidazole have been associated with VRE colonization. Non-antimicrobial risk factors (e.g., increased duration of exposure to individuals colonized with VRE and close proximity to other colonized patients) increase the likelihood of VRE exposure [2]. According to recent surveys, Enterococci remain in the top 3 most common pathogens that cause nosocomial infections. Nosocomial Enterococcal infections typically occur in very ill debilitated patients who have been exposed to broad-spectrum antibiotics.

These emphasize the need for their identification from the clinical specimens and also differentiate them from other group D streptococci which are generally more sensitive to the antimicrobial agents.

Keeping these in mind the present study has been undertaken in the Department of Microbiology, Shri Sathya Sai Medical College \& Research Institute, Kancheepuram. To study the prevalence of Enterococcus species from various clinical specimens in Shri Sathya Sai Medical College \& Research Institute with special reference to speciation \& their resistance to Vancomycin.

\section{Aim and objectives}

1. To process all the clinical samples from various departments in our hospital, for the isolation of Enterococci sp.

2. To speciate the isolated Enterococci \& to have the resistance pattern of the isolates to Vancomycin

3. To know the prevalence of Enterococcal infections in our hospital,

4. To know the resistance pattern of the isolates to Vancomycin.

\section{Materials and Methods}

A total of 928 samples were collected from both Out-Patient and In -Patient from all clinical departments of Shri Sathya Sai Medical College \& Research Institute, during one year period.

\section{Specimens collected}

- Urine

- Pus
- Blood

- Endotracheal aspirates

- Sputum

\section{Collection and transport of specimen Data collection}

Complete data about the patients such as name, age, sex, hospital number, date, time of collection, source of specimen and details about the clinical history was recorded before the specimen was processed.

All specimens for microbiological processing were collected in appropriate sterile containers. For urine collection the patients were given a sterile, screw capped, wide mouth, leak proof, labeled with name of the patient and number of the sample on the containers and patients were advised how to collect the midstream urine to avoid contamination.

For sputum collection a well coughed out sample was collected in sterile, wide mouthed, screw capped container labeled with name and number of the specimen.

Pus, other aspirates were collected in a test tube and pus from the site of lesion like abscesses, boils, infected wounds etc. was collected by using at least two sterile cotton swabs

Blood sample was collected carefully by first choosing the vein and then the skin was prepared by disinfecting with $70 \%$ alcohol, dried and then $2 \%$ of tincture iodine was applied and allowed it to dry. Then the vein was punctured with sterile needle and $5 \mathrm{ml}$ of blood was collected without touching the site. Collected blood sample was then inoculated into blood culture bottles and then transported to the laboratory immediately for the incubation.

Endotracheal aspirates were collected by using sterile 12 Gauge endo tracheal suction catheter tube. Suction catheter was connected to the suction pump and passed through endotracheal tube. In case of purulent secretion the endotracheal suction catheter tips were collected using sterile scissors into the sterile container (screw capped). In case of thick or dry secretions with clinical diagnosis of Pneumonia, sterile normal saline is pushed into endotracheal tube and then suction was done for the aspirate. The samples were transported to microbiology laboratory within 15 minutes. Specimens were processed as soon as they were obtained.

\section{Processing of samples}

The samples were plated on to Mac Conkeys agar, blood agar, nutrient agar, Pfizer selective media and incubated at $37{ }^{\circ} \mathrm{C}$ for 24 48 hours.

The plates were examined for growth after 24 hours. If growth was observed, colony morphology and Gram stain morphology were studied. If no growth was observed, the plates were further incubated for the next 24 hours.

The colonies were further identified by hanging drop preparation and biochemical reactions. The Gram positive and Gram negative organisms were differentiated and identified by a battery of tests as per standard protocols. The Gram negative organisms are excluded and not further processed as the study is on only Enterococci.

\section{Identification of Enterococci}

Enterococci are identified microscopically by their typical arrange- 
ment in Gram stain in which they are arranged in pairs and in obtuse angles and Catalase test is done to differentiate between Staphylococci and Group D Streptococci.

Further to differentiate between other groups of Streptococci, tests like Salt tolerance tests, Heat resistance test at $60^{\circ} \mathrm{C}$ for 30 minutes, Bile esculin test where Enterococci can grow in the salt concentration of $6.5 \%$, Pfizer selective media, they also can tolerate the temperature of $60^{\circ}$ for 30 minutes and grows on $40 \%$ bile where all the other groups of Streptococci are inhibited (Fig. 1) ${ }^{6}$.
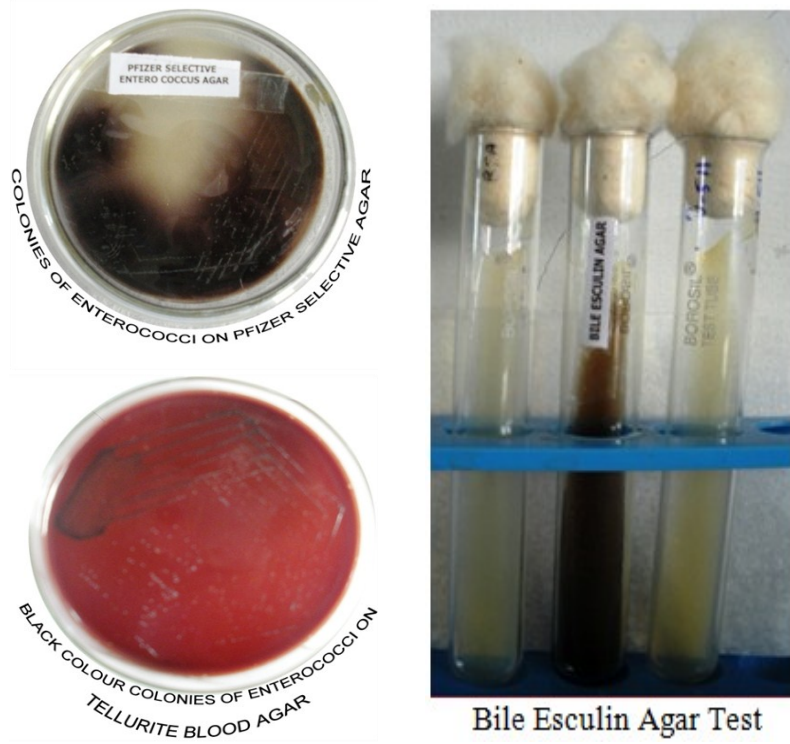

Bile Esculin Agar Test

Fig. 1-

\section{Identification of species}

The speciation is done by subjecting the isolates with a battery of biochemical and other tests like sugar fermentation (Glucose, Sucrose, Mannitol, Raffinose, Arabinose and Sorbitol). L-Arginine decarboxylase, Pyruvate fermentation, Motility testing is done and results interpreted (Fig. 2 and 3 a \& b)

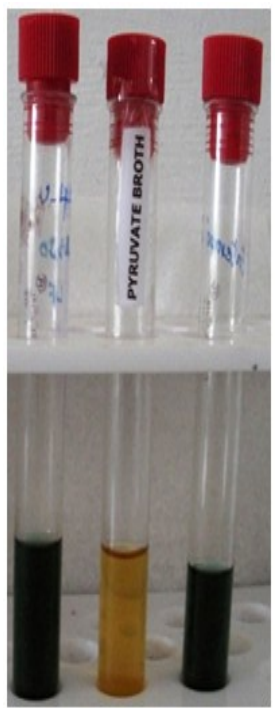

Pyruvate Broth Test

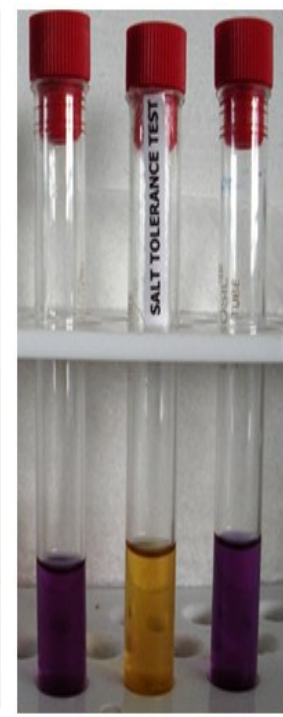

Salt Tolerance Test
Moller L-Arginine Decarboxylase Test

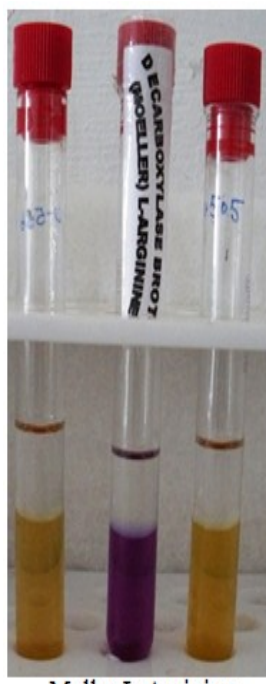

Fig. 2-

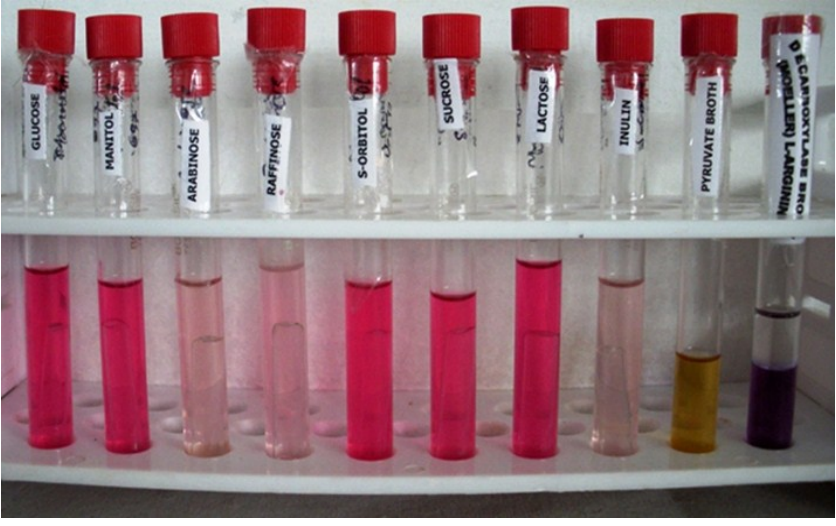

Fig. 3a- Sugar Fermentation Test for Enterococcus

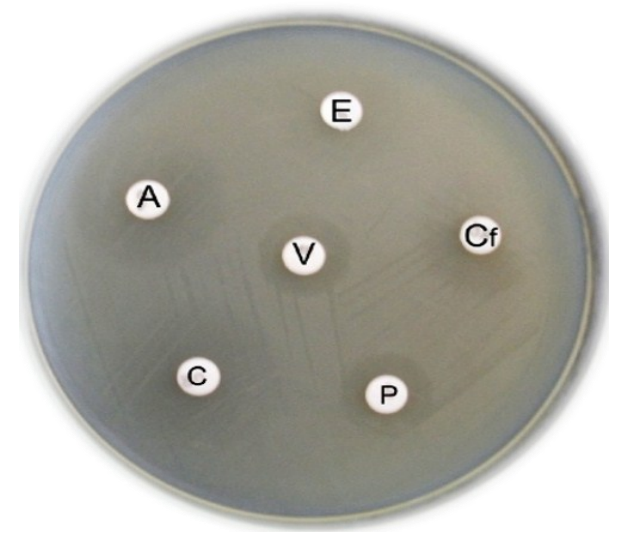

Fig. 3b- Antibiotic Sensitivity Test by Kirby - Bauer Disc Diffusion Method

\section{Detection of Anti microbial susceptibility pattern Disc diffusion method}

Anti microbial susceptibility pattern was done in Mueller Hinton agar plate by Kirby Bauer Disc diffusion method as recommended by NCCLS.

\section{Requirements}

\section{Mueller Hinton Agar}

- Bacterial inoculum adjusted to 0.5 Mac - Farland Standard Incubation time and temperature-

- $37^{\circ} \mathrm{C}$ for $16-18$ hours.

Lawn culture of the organism is made over the Mueller Hinton agar (Hi Media). with the suspension of organism cultured in peptone water which is standardized with $0.5 \mathrm{Mc}$ Farland standard. After inoculum has dried specific antibiotics discs were placed 2 $\mathrm{cm}$ apart from each other with sterile forceps and was incubated for $18-24$ hours at $37^{\circ} \mathrm{C}$ aerobically. The zone size was interpreted according to the reference chart provided by the manufactures, according to NCCLS standards for each organism.

The Antibiotic discs used for Gram positive cocci were: Penicillin $\mathrm{G}$ (10 units/disc), Erythromycin (15mg/disc), Ciprofloxacin (30mg/disc), Gentamicin (50mg/disc), Nalidixic acid (30 mg/disc), Vancomycin (30mg/disc).

Dilution methods- (Tube \& Agar dilution) 


\section{Materials required}

Sterile graduated pipettes of $10 \mathrm{ml}, 5 \mathrm{ml}, 2 \mathrm{ml}$ and $1 \mathrm{ml}$.

Sterile capped $7.5 \times 1.3 \mathrm{~cm}$ tubes, Pasteur pipettes, overnight broth culture of test and control organisms (same as for disc diffusion tests), Vancomycin antibiotic in powder form is obtained from the Hi-Media manufacturer accompanied by a statement of its activity in $\mathrm{mg} /$ per $\mathrm{ml}$ solvent for the antibiotic, sterile Distilled Water and nutrient broth medium for testing the isolate.

\section{Preparation of stock solutions}

Stock solutions were prepared using the formula (1000/P) X V X $\mathrm{C}=\mathrm{W}$, where $\mathrm{P}=$ potency of the antibiotic base, $\mathrm{V}=$ volume in $\mathrm{ml}$ required, $C=$ final concentration of solution and $W=$ weight of the antimicrobial to be dissolved in $\mathrm{V}$.

\section{Medium used for broth and Agar dilution}

Brain heart infusion broth is used for testing the isolates by broth dilution. $5 \mathrm{ml}$ of broth is added after sterilization to sterile test tubes. Mueller Hinton Agar is used for agar dilution testing.

\section{Preparation of broth and agar dilutions \\ Stock solution}

Stock solution can be prepared using the formula

1000

$$
\longrightarrow \mathrm{P} \times \mathrm{C}=\mathrm{W}
$$

Where $\mathrm{P}=$ Potency given by the manufacturer in relation to the base

$\mathrm{V}=$ Volume in $\mathrm{ml}$ required

$\mathrm{C}=$ Final concentration of solution (multiples of 1000)

$\mathrm{W}=$ Weight of the antimicrobial to be dissolved in the volume $\mathrm{V}$.

Preparation of stock solutions and various concentrations of dilutions for both tube dilution and agar dilution are mentioned below.

\section{ANNEXURE - I}

Preparation of antibiotic solution for broth and agar dilutions Stock solution I,II,III

Stock solution - I $(10,000 \mathrm{mg} / \mathrm{ml})$ -

$20 \mathrm{ml}$ solution is prepared by mixing $210.52 \mathrm{mg}$ of powder base whose potency is $950 \mathrm{mg}$ per gram, with sterile distilled water

$$
W=\frac{1000}{950} \times 20 \times 10=210.52 \mathrm{mg}
$$

Stock solution - II $(1000 \mathrm{mg} / \mathrm{ml})$ -

$1 \mathrm{ml}$ of solution from the stock solution-l is transferred to $9 \mathrm{ml}$ of distilled water (stock solution-II) which gives a concentration of $1000 \mathrm{mg} / \mathrm{ml}$.

\section{Stock solution - III (100mg/ml)-}

$0.1 \mathrm{ml}$ of stock solution- I is transferred to $9.9 \mathrm{ml}$ of distilled water

\begin{tabular}{|c|c|c|c|}
\hline Stock soln-l Ist tube(128mg/L) & IInd tube(64mg/L) & IIIrd tube(32mg/L) & IVth tube (16mg/L) 32 \\
\hline $10,000 \mathrm{mg} / \mathrm{L} 256 \mu \mathrm{l}$ from soln-I & $128 \mu$ f from soln-I & $64 \mu \mathrm{l}$ from soln-I & $\mu \mathrm{l}$ from soln-I \\
\hline Stock soln- Vth tube(8mg/L) & Vlth tube(4mg/L) & Vllth tube(2mg/L) & \\
\hline II $1000 \mathrm{mg} / \mathrm{L} 160 \mu \mathrm{l}$ from soln-II & $80 \mu$ from soln-II & $40 \mu$ l from soln-II & \\
\hline 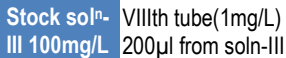 & $\begin{array}{l}\text { IXth tube }(0.5 \mathrm{mg} / \mathrm{L}) \\
100 \mu \text { l from soln-III }\end{array}$ & $\begin{array}{l}\text { Xth tube }(0.25 \mathrm{mg} / \\
\text { L) } 50 \mu \mathrm{l}=\end{array}$ & $\begin{array}{l}\text { Xlth tube (Control) Free } \\
\text { from Antibiotics }\end{array}$ \\
\hline
\end{tabular}
(stock solution-III) which gives a concentration of $100 \mathrm{mg} / \mathrm{ml}$.
At least three to five well-isolated colonies of the same morphological type are selected from an agar plate culture. The top of each colony is touched with a loop and the growth is transferred into a tube containing 4 to $5 \mathrm{ml}$ of a Nutrient broth medium.

The broth culture is incubated at $37^{\circ} \mathrm{C}$ until it achieves or exceeds the turbidity of the 0.5 McFarland standard 2 - 6 hours.

The turbidity of the actively growing broth culture is adjusted with sterile saline or broth to obtain turbidity optically comparable to that of the $0.5 \mathrm{McF}$ arland standards. Finally suspension containing approximately $1 \times 10^{6} \mathrm{CFU} / \mathrm{ml}$ for Enterococci ATCC 29212, isolates is compared with $0.5 \mathrm{McF}$ arland standards in adequate light with a white background and contrasting black lines.

\section{Procedure}

1- $2 \mu \mathrm{l}$ of inoculum is transferred to the agar plates which give a final concentration $\mathrm{f} 10^{4} \mathrm{cfu} / \mathrm{ml}$, similarly $0.1 \mathrm{ml}$ of inoculum. is aseptically transferred to each of the different concentration test tubes. A control tube and an agar plate also inoculated which does not have the antibiotics. The plates and tubes are incubated at $37^{\circ} \mathrm{C}$ for 24 hours along with controls.

\section{Reading of result}

MIC is expressed as the lowest dilution, which inhibits the growth which is judged by lack of turbidity in the tube. Because very faint turbidity may be given by the inoculum itself, the inoculated tube kept in the refrigerator overnight may be used as the standard for the determination of complete inhibition.

Standard strain of known MIC value Enterococci ATCC 29212 also run along with the test to check the reagents and conditions. The results were recorded in a standard chart for both broth and tube dilution and interpreted.

\section{Quality control of media and other tests}

Each batch of medium was tested for sterility by selecting a plate at random and incubated at $37^{\circ} \mathrm{C}$ for $24-48$ hours. Further the plates were inoculated with the positive and negative control organisms to know the performance of the media.

\section{Results}

A total of 928 samples were collected from both out and in patients. Among these 647(69.72\%) were culture positive and 281 (30.28) were culture negative (Table-1). Gender wise distribution of samples were, males $511(55.06 \%)$ and females $417(44.94 \%)$ (Table-2). Age wise distribution of samples, the youngest patient was 1 year and oldest was 80 years old (Table- 3 ). Distribution of different types of samples like Urine, Pus, ET-aspirates and Blood etc (Table-4). Prevalence of Enterococci and other isolates in the total number 647 of positive samples; Enterococci were 100 (15.46\%) (Table-5). Prevalence of Enterococci among different samples Enterococci was isolated more from urine sample $59 \%$ (Table-6). All 100 isolates of Enterococci were identified as Enterococcus faecalis (Table- 7 ).

Antimicrobial resistance of Enterococcus faecalis isolates (100) by disk diffusion method by battery of antibiotic (Table- 8). Among al the isolates (100), one isolate showed MIC of $34 \mu \mathrm{g} / \mathrm{ml}$ in both macrodilution (Table- 9 \& Fig. 4) and agar dilution methods (Table - 10 and Fig. 5) which is considered as resistance. 
Table 1- Analysis of Total samples

\begin{tabular}{|lll|}
\hline Total samples & No. of samples & Percentage \\
\hline No of culture positives & 647 & 69.72 \\
No of culture negatives & 281 & 30.28 \\
Total & 928 & 100 \\
\hline
\end{tabular}

Table 2- Gender wise distribution of samples

\begin{tabular}{|lll|}
\hline Gender & No of samples & Percentage \\
\hline Males & 511 & 55.06 \\
Females & 417 & 44.94 \\
Total & 928 & 100 \\
\hline
\end{tabular}

Table 3- Age wise distribution of total samples

\begin{tabular}{|l|ll|}
\hline Age & No. of samples & Percentage \\
\hline $0-10$ & 57 & 6.14 \\
$11-20$ & 82 & 8.84 \\
$21-30$ & 102 & 10.99 \\
$31-40$ & 147 & 15.84 \\
$41-50$ & 170 & 18.32 \\
$51-60$ & 162 & 17.46 \\
$61-70$ & 133 & 14.33 \\
$71-80$ & 75 & 8.08 \\
Total & 928 & 100 \\
\hline
\end{tabular}

Table 4- Distribution of different types of samples in the study

\begin{tabular}{|lll|} 
Type of sample & No of samples & Percentage \\
\hline Urine & 374 & 40.30 \\
Pus and other body fluids & 296 & 31.90 \\
ET aspirates & 91 & 9.80 \\
Blood & 167 & 18.00 \\
Total & 928 & 100 \\
\hline
\end{tabular}

Table 5- Prevalence of enterococci and other isolates in the total no. of positive samples
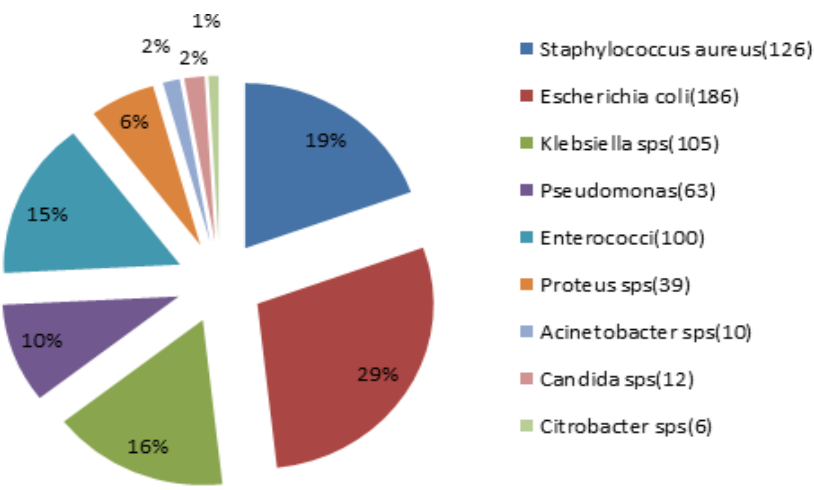

Table 6- Prevalence of enterococci in different samples

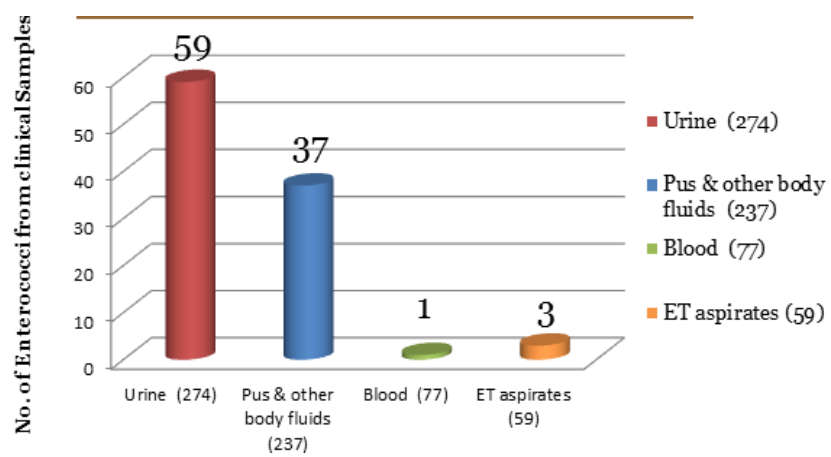

Table 7- Species identities of Enterococci from total isolates

\begin{tabular}{|lll|}
\hline Species & No. of isolates & Percentage \\
\hline E. faecalis & 100 & 100 \\
Total & 100 & 100 \\
\hline
\end{tabular}

Table 8- Antimicrobial resistance profiles of $E$. faecalis isolates by Disk-diffusion method $(n=100)$

\begin{tabular}{|lll} 
Antibiotics & Resistance & Percentage \\
\hline Penicillin & 78 & 78 \\
Erythromycin & 82 & 82 \\
Ciprofloxacin & 82 & 82 \\
Gentamicin & 71 & 71 \\
Nalidixic acid & 91 & 91 \\
Vancomycin & 1 & 1 \\
\hline
\end{tabular}
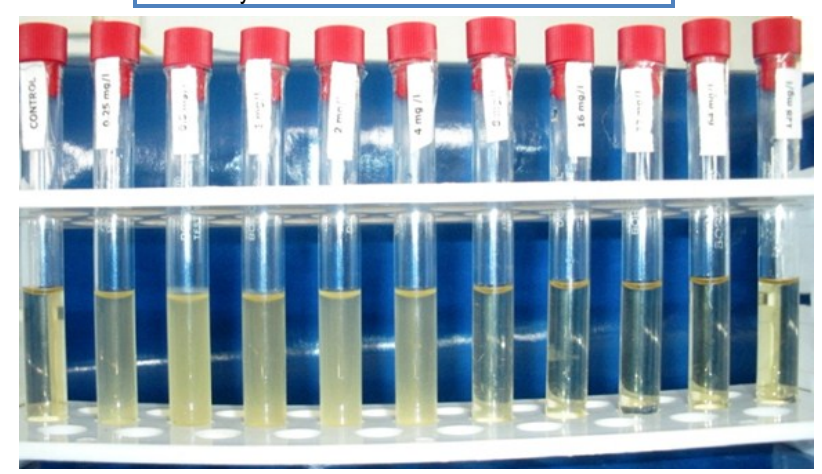

Fig. 4- Minimum Inhibitory Con. Test by Macrodilution Method for Enterococcus ATCC 29212

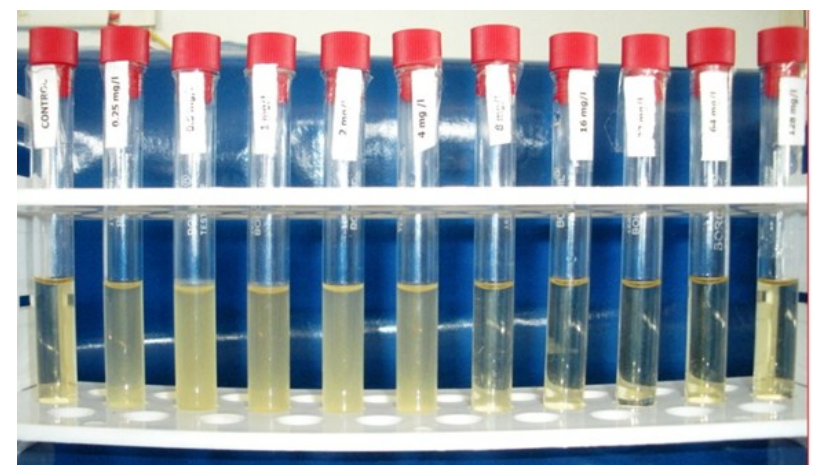

Fig. 4- Minimum Inhibitory Con. Test by Macrodilution Method for Enterococcus

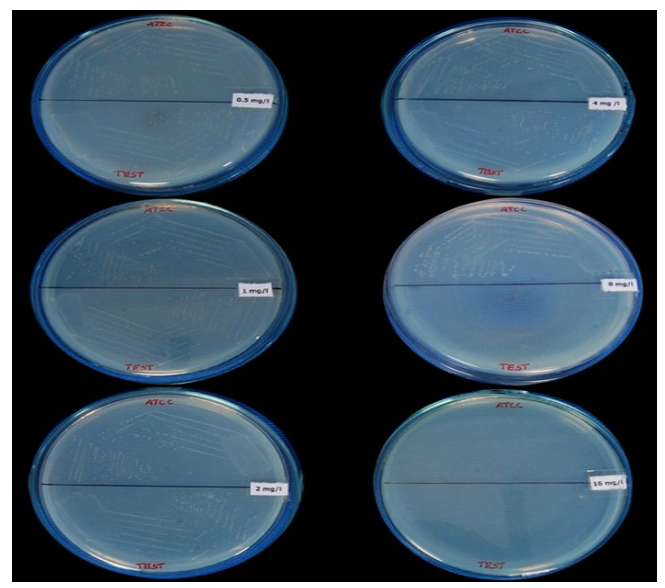

Fig. 5- Minimum Inhibitory Concentration For Test Enterococci and ATCC 29212 by Agar Dilution Method 


\section{Discussion}

Vancomycin-resistant Enterococci have been increasingly reported worldwide since its first description in 1987. The present study documents the phenotypic character and resistant pattern of Enterococci to vancomycin over 1-year period from different clinical samples at Shri Sathya Sai Medical \& Research Institute.

The study was conducted to know the prevalence of Enterococci $s p$ in our hospital, to know the resistance pattern of the isolates to Vancomycin.

Recently Enterococci are being isolated more frequently from the clinical specimens and are gaining upper hand in causation of nosocomial infections. CDC indicates that enterococci are the second leading cause of nosocomial infection, joining Escherichia coli, Pseudomonas aeruginosa and Staphylococcus aureus in the list of most prevalent pathogens. During the 12 months of our study, Enterococci were isolated from various clinical specimens with the prevalence rate of $15.46 \%$. The wide variety of infectious material from which Enterococci was isolated was found similar to those obtained in other studies. (7)

In prevalence Escherichia coli remains at top of the table with 186 (28.75\%) followed by Staphylococcus aureus 126 (19.46\%), Klebsiella sp 105 (16.23\%), Enterococci sp 100 (15.46\%), Pseudomonas sp 63 (9.74\%) and Proteus sp 39 (6.03\%). The percentage in our study correlated with the study done by P.J.Desiai etal where they reported a prevalence rate of $22.19 \%$. Dr. Abdel -Moti Khyri Al Jarousha Mr. Ahmed Mohammed Saed / Hassan Afifi which is $18 \%(8)$.

P.J.Desiai etal reported $8.92 \%$ of Enterococci isolation in urine which correlates well with the present study where 59 Enterococci isolates are isolated, $(9.12 \%)$, which shows the frequent and higher isolation of Enterococci is from urine sample followed by pus and other body fluids 37 isolates $(5.72 \%)$, endotracheal aspirates 3 isolates $(0.46 \%)$ and from blood 1 isolate $(0.15 \%)$ respectively. The species isolated in the study was Enterococcus faecalis $(100 \%)$, Incidence of Enterococcal infection is higher in the age group, between 51-60 years.

By Kirby Bauer disk diffusion method, Erythromycin and ciprofloxacin resistance was $82 \%$ and $83.2 \%$ respectively which is alarmingly high percentage. Penicillin and Gentamicin showed $78 \%$ and $71 \%$ resistance. 99 strains showed $100 \%$ sensitive to Vancomycin by KBDDM.

One strain showed Vancomycin resistance in our study with $1 \%$ and $15 \%$ intermediate resistance in our present study which is also reported by other Indian studies (9). In contrast to reports from U.S.A where Vancomycin resistance is more common. In our study, about 12 of Enterococcal strains showed raised MIC of 8 $\mu \mathrm{g} / \mathrm{ml}$.

\section{Conclusion}

Precise identification of Enterococci to species level enables us, to assess the species-specific antimicrobial resistance characteristics, apart from knowing the epidemiological pattern and their clinical significance in human infections. Further as shown in our study, the increase in the rate of prevalence of the Enterococcus species and the emergence of multidrug resistance among them, highlights the significance of rapid and accurate identification of Enterococci to the species level for initiating appropriate therapeutic regimen and reemphasize the importance of the implementa- tion of appropriate infection control measures to limit the nosocomial spread of these Enterococci species in any nosocomial setting.

Vancomycin in combination with an aminoglycoside has synergistic activity against enterococci and is recommended as the drug of choice in patients with ampicillin- and penicillin-resistant. However, enterococci are becoming increasingly resistant to traditional antibiotic therapy. In addition to high-level aminoglycoside resistance and ampicillin resistance, rapid spread of vancomycin resistance has resulted in limited therapeutic alternatives. Important to maintain regular surveillance of antibiotic susceptibilities so that changes in their pattern can be detected early.

As MIC detection is a laborious procedure all Enterococcal isolates can be screened by vancomycin agar screen method containing $6 \mu \mathrm{g} / \mathrm{ml}$ which is suggested by NCCLS and only those isolates which are positive by this method can be tested further for vancomycin MIC, as both the methods correlated well in this study.

Effective detection of vancomycin resistance in laboratory helps in reducing the morbidity and mortality due to VRE in hospitalized patients.

\section{Reference}

[1] Ssusan L. Fraser Infectious Diseases Service, Walter Reed Army Medical Center, Julia Lim, Army Medical Center, Curtis J Donskey, Case Western Reserve University, Robert A Salata, Case Western Reserve University School of Medicine.

[2] Yesim Cetinkaya, Pamela Falk and Glen Mayhall C. Department of Healthcare Epidemiology and Division of Infectious Diseases, University of Texas Medical Branch at Galveston, Galveston, Texas.

[3] Boyce J.M. (1997) Infect. Dis. Clin North Am. 11, 367-384.

[4] Robin Patel. Infectious Diseases Research Laboratory, Mayo Clinic and Foundation, 200 First St. S. W.Rochester, MN 55905, USA.

[5] Handwerger S., Raucher B., Altarac D., Manka J., Marchione S., Sing K.V., Murray B.E., Wolff J. and Walters B. (1993) Clin. Infect. Dis. 16, 750-755.

[6] Topley Wilsons microbiology and microbial infections $10^{\text {th }}$ edition volume 2 Bacteriology 883-902.

[7] Desai P.J., Pandit D, Mathur M. and Gogate A. (2001) Indian Journal of Medical Microbiology, 19(3), 132-137.

[8] Abdel-Moti Khyri Al Jarousha, Ahmed Mohammed Saed (2008) Prevalence of Multidrug Resistant Enterococci in Nosocomial Infection, Hassan Afifi. J. Al-Aqsa Unv..

[9] De A., Bindlish A.et.al. Indian journal of medical microbiology, 27(4) 375,378 . 
Table 9- MIC range of E. faecalis for selected drug Vancomycin (Macrodilution method $n=100$ )

\begin{tabular}{|c|c|c|c|c|c|c|c|c|c|c|}
\hline Drug conc ( $\mu \mathrm{g} / \mathrm{ml})$ & $\begin{array}{l}0.25 \\
(\mu \mathrm{g} / \mathrm{ml})\end{array}$ & $\begin{array}{l}0.5 \\
(\mu \mathrm{g} / \mathrm{ml})\end{array}$ & $\begin{array}{l}1 \\
(\mu \mathrm{g} / \mathrm{ml})\end{array}$ & $\begin{array}{l}2 \\
(\mu \mathrm{g} / \mathrm{ml})\end{array}$ & $\begin{array}{l}4 \\
(\mu \mathrm{g} / \mathrm{ml})\end{array}$ & $\begin{array}{l}8 \\
(\mu \mathrm{g} / \mathrm{ml})\end{array}$ & $\begin{array}{l}16 \\
(\mu \mathrm{g} / \mathrm{ml})\end{array}$ & $\begin{array}{l}32 \\
(\mu \mathrm{g} / \mathrm{ml})\end{array}$ & $\begin{array}{l}64 \\
(\mu \mathrm{g} / \mathrm{ml})\end{array}$ & $\begin{array}{l}128 \\
(\mu \mathrm{g} / \mathrm{ml})\end{array}$ \\
\hline Control ATCC (29212) & --- & 1 & --. & --- & --- & --- & --- & --- & --- & --- \\
\hline MIC value (No. of isolates) & --- & --- & --- & 61 & 23 & 12 & 3 & 1 & --- & --- \\
\hline Percentage $\%$ & --- & --- & --- & 61 & 23 & 12 & 3 & 1 & --- & --- \\
\hline
\end{tabular}

Table 10- MIC range of E. faecalis for selected drug Vancomycin (Agar dilution method $n=100$ )

\begin{tabular}{|c|c|c|c|c|c|c|c|c|c|c|}
\hline Drug conc ( $\mu \mathrm{g} / \mathrm{ml})$ & $\begin{array}{l}0.25 \\
(\mu \mathrm{g} / \mathrm{ml})\end{array}$ & $\begin{array}{l}0.5 \\
(\mu \mathrm{g} / \mathrm{ml})\end{array}$ & $\begin{array}{l}1 \\
(\mu \mathrm{g} / \mathrm{ml})\end{array}$ & $\begin{array}{l}2 \\
(\mu \mathrm{g} / \mathrm{ml})\end{array}$ & $\begin{array}{l}4 \\
(\mu \mathrm{g} / \mathrm{ml})\end{array}$ & $\begin{array}{l}8 \\
(\mu \mathrm{g} / \mathrm{ml})\end{array}$ & $\begin{array}{l}16 \\
(\mu \mathrm{g} / \mathrm{ml})\end{array}$ & $\begin{array}{l}32 \\
(\mu \mathrm{g} / \mathrm{ml})\end{array}$ & $\begin{array}{l}64 \\
(\mu \mathrm{g} / \mathrm{ml})\end{array}$ & $\begin{array}{l}128 \\
(\mu \mathrm{g} / \mathrm{ml})\end{array}$ \\
\hline Control ATCC (29212) & --- & 1 & --- & --- & --- & -- & --- & --- & --- & --- \\
\hline MIC value (No. of isolates) & --- & --- & --- & 64 & 24 & 9 & 2 & 1 & --- & --- \\
\hline Percentage $\%$ & --- & --- & --- & 64 & 24 & 9 & 2 & 1 & --- & --- \\
\hline
\end{tabular}

